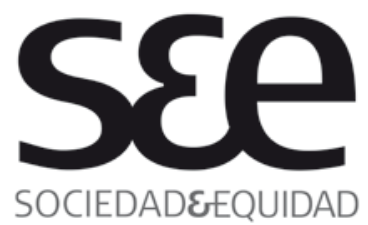

SOCIEDADEEQUIDAD

\section{Reseña: Los nuevos vecinos de la Mancomunidad del Sureste. LoS inmigrantes y su inserción en Torre Pacheco, Fuente Álamo y La Unión (Murcia) $(*)$}

The new neighbors in the southeast community. Immigrants and their insertion in Torre Pacheco, Fuente Álamo y La Unión (Murcia)

$\begin{array}{ll}\text { Nombre: } & \text { Olga Achón Rodríguez } \\ \text { Filiación: } & \text { Universidad de Barcelona } \\ \text { País: } & \text { España } \\ \text { Correo: } & \text { olga_achon@yahoo.es }\end{array}$

\title{
Resumen
}

En el presente artículo se reseña una investigación realizada sobre el proceso de inserción de los inmigrantes en los municipios de Torre Pacheco, La Unión y Fuente Álamo, todos ellos pertenecientes a la comarca murciana del Campo de Cartagena. El objetivo principal de la misma es conocer la realidad social de los inmigrantes que residen en estos municipios y generar un diagnóstico de la situación de los vecinos extranjeros con el que elaborar un plan de integración desde la Mancomunidad de los Servicios Sociales del Sureste de Murcia. El principal interés de los autores ha sido mostrar el complejo proceso de inserción de los extranjeros así como dar explicación a las dinámicas que tal proceso provoca en las relaciones sociales de vecindad. La forma de inserción social que los inmigrantes han experimentado en los municipios que componen el espacio de la investigación y la posición social que éstos ocupan en la actualidad es objeto, entonces, de este trabajo.

(*)Torres, F. (Dir.) (2007) Los nuevos vecinos de la Mancomunidad del Sureste. LoS inmigrantes y su inserción en Torre Pacheco, Fuente Álamo y La Unión (Murcia). Murcia: Ediciones de la Universidad de Murcia.

(**) La autora es Doctor en Antropología, parte del GRECS- Grupo de Investigación sobre Exclusión y Control Social. Universidad de Barcelona. Sus líneas de investigación son: Migración subsahariana y magrebí en los pueblos de la provincia de Lleida (Cataluña, España) y sus consecuencias en su acceso a la vivienda, reclutamiento de trabajadores en origen mediante sistemas de importación de mano de obra y sus consecuencias en los derechos de los trabajadores. 


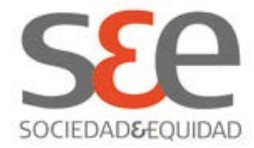

\title{
Palabras Claves
}

Inmigración Internacional, Inserción Residencial, Vivienda Inmigrante, Inserción Educativa, Inserción Sanitaria y de Servicios Sociales, Participación Cívica.

\begin{abstract}
This article is a review of the results of a research carried out regarding the integration of immigrant population in "Torre Pacheco", "La Unión" and "Fuente Alamo", a group of counties that belong to the Murcian region of Campo de Cartagena. It's main goal is to inform about the social reality of immigrants that live in this region and generate a diagnosis of the situation of the foreign neighbors that live there in order to create an integration plan from the community of south eastern Social Services of Murcia. The main objective of the authors has been to show the complex process of insertion that foreigners have to face and to explain the effect that such processes cause in the neighborhood social relations. Hence, the social integration that immigrants have experienced in the communities under study and the social position they nowadays occupy are the main subjects of this study.
\end{abstract}

\section{Keywords}

International Immigration, Residential Insertion, Housing for Immigrants, School Insertion, Insertion in Social Services and Civic Participation.

$* * *$

El trabajo que a continuación se reseña es fruto de una investigación realizada sobre el proceso de inserción de los inmigrantes en los municipios de Torre Pacheco, La Unión y Fuente Álamo, todos ellos pertenecientes a la comarca murciana del Campo de Cartagena ${ }^{2}$. El objetivo principal de la misma es conocer la realidad social de los inmigrantes que residen en estos municipios y generar un diagnóstico de la situación de los vecinos extranjeros con el que elaborar un plan de integración desde la Mancomunidad de los Servicios Sociales del Sureste de Murcia ${ }^{3}$. El principal interés de los autores ha sido

${ }^{2}$ El Campo de Cartagena es una comarca natural de la comunidad autónoma Región de Murcia. Sin delimitación administrativa precisa, tiene sus límites al norte y al oeste en la Sierra de Carrasco y, al sur en el mar Mediterráneo y al este en el mar Menor. Los municipios que componen esta comarca son Cartagena, Torre-Pacheco, San Pedro del Pinatar, San Javier, La Unión, Los Alcázares y Fuente Álamo de Murcia.

${ }^{3}$ Este organismo administrativo ha desaparecido en la actualidad. Según información extraída del diario La Opinión de Murcia, fue el 21 de octubre del año 2011 cuando se acordó la liquidación definitiva de la Mancomunidad de Servicios Sociales del Sureste mediante el reparto equitativo del remanente líquido de tesorería. Esta decisión se 


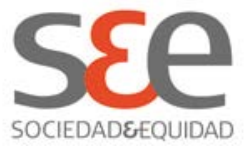

mostrar el complejo proceso de inserción de los extranjeros así como dar explicación a las dinámicas que tal proceso provoca en las relaciones sociales de vecindad. La forma de inserción social que los inmigrantes han experimentado en los municipios que componen el espacio de la investigación y la posición social ${ }^{4}$ que éstos ocupan en la actualidad es objeto, entonces, de este trabajo para el que se ha tratado, primeramente, de perfilar una suerte de pre-historia de la inmigración en los municipios mencionados y, después, analizar el fenómeno de inserción desde diversos planos.

Como se indica en su texto introductorio el diseño del trabajo se ordena al entorno de seis dimensiones: los aspectos socio-demográficos de la inmigración en la zona, la situación laboral, la inserción residencial y la vivienda inmigrante, la inserción educativa de los hijos de los inmigrantes, la sanidad y los servicios sociales y la convivencia y la participación cívica. El estudio de cada una de estas dimensiones lleva a los autores a la detección de obstáculos y, también, de aquéllos aspectos considerados más positivos para avanzar en el proceso de integración; y aunque en la realidad estas dimensiones se encuentran en constante interrelación, el diseño de la investigación ha permitido tanto explicar determinadas dinámicas como advertir algunas tendencias futuras ${ }^{5}$. Una de aquéllas es la mayor diversificación de los orígenes de procedencia de los extranjeros que llegan

tomó tras el acuerdo unánime de los miembros de la Comisión Liquidadora de dicho organismo, compuesta por los alcaldes, secretarios e interventores de los municipios de Torre Pacheco, La Unión y Fuente Álamo. Con esta reunión se puso definitivamente punto y final a la Mancomunidad, explicando que cada ayuntamiento gestionaría en adelante sus servicios sociales. http:// www. laopiniondemurcia. es/ municipios/2011/ 11/ 11/ trabajadoresmancomunidad-servicios-sociales-ahogados/363537. html [18/ 04/ 2013]

${ }^{4}$ Sayad, A. (1994) “Qu'est-ce que I'intégration», Hommes \& Migrations, 1182, 8-14. Según cita y bibliografía tomada de los autores.

${ }^{5}$ La interpretación de los autores acerca del devenir del proceso de integración de la población extranjera en los municipios considerados en la investigación ha de comprenderse en el contexto previo a la crisis económica cuyo origen suele situarse entre finales del año 2007 e inicios del 2008. Esta aclaración debe servir para hacer consciente al lector del trabajo que las tendencias futuras a las que apuntan los autores, como la mejora de las condiciones de inserción, parecen haberse visto detenidas, entre otros factores, por el recorte de recursos destinados a servicios sociales que se dirigían para la atención de población en riesgo social, por el estancamiento de los precios del trabajo, la reciente incorporación de población autóctona en sectores económicos que con anterioridad a la crisis ocupaban los extranjeros -quedando estos últimos desplazados-, y por el progresivo aumento de la población extranjera en las listas de desempleados, entre otros factores. 


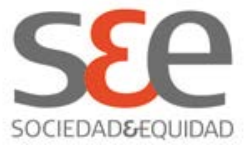

para asentarse en la región, la evolución del carácter crecientemente familiar del vecindario inmigrante y la mejora de las condiciones de inserción. Eje transversal de esta investigación es la variable convivencia que empapa de arriba abajo todas y cada una de las dimensiones que en ella se abordan. No podía ser de otro modo si la pregunta inicial de los investigadores es acerca del desarrollo del proceso local de inserción. Asimismo, la variable de género incide en la manera en que debe tratarse el problema de la inserción, pues a todas luces el modo en que las mujeres inmigrantes se insertan en la sociedad receptora es distinto al modo en que lo hacen los hombres, principalmente por los prejuicios que operan en contra de las mujeres extranjeras, dependiendo de su origen nacional, y por la concepción que cada cultura posee de la mujer y el rol que debe desempeñar en sociedad, especialmente en el espacio público.

Han sido una combinación de métodos cuantitativos y cualitativos los que han servido para la extracción de datos y para su posterior interpretación. Las opiniones, percepciones y discursos han sido contrastados con datos estadísticos provenientes de los padrones municipales y regionales, entre otros instrumentos de análisis cuantitativo. Por otro lado las memorias de programas específicos dirigidos a inmigrantes realizados por la Mancomunidad de Servicios Sociales del Sureste, así como por otros servicios y Consejerías, han servido a los autores para obtener información sobre la condición social de los extranjeros avecindados en los municipios que componen la muestra. Sin embargo, las técnicas de investigación que se han utilizado directamente sobre los suj etos considerados relevantes para el análisis son las entrevistas grupales y las individuales, dependiendo del tipo de discurso o información que se ha pretendido obtener. El análisis realizado por los autores y su presentación ha sido esencial para llegar a comprender la situación de los inmigrantes en los municipios considerados y poder así comparar tal escenario otras realidades similares. El investigador de los procesos de inserción y de integración puede encontrar en este texto un ejemplo de análisis de una realidad tan compleja como lo es la situación social de los extranjeros. Nos gustaría aquí mostrar algunos de sus resultados. Atendiendo a las posibilidades de extensión de esta recensión nos centraremos en la exposición del análisis que los investigadores han realizado en el campo de la inserción laboral y la inserción residencial, con el objeto, decíamos, de mostrar algunas de sus conclusiones.

Prestando atención al primer capítulo podemos ver como se ha tratado, primeramente, de esbozar una breve historia sobre la llegada de los primeros jornaleros marroquíes, inicialmente a Torre Pacheco y Fuente Álamo a mediados de los años 80, cuya inserción vino marcada por la precariedad y la segregación, y sobre la transformación tanto de los municipios en lugares multiculturales, como de su economía, cuyo despegue se debe a la expansión de la agricultura intensiva. Un modo de explotación salarial se instauró en el 


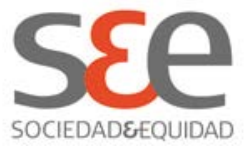

campo murciano en este período cuyas principales consecuencias fueron la alta rotación de jornaleros y las prácticas paternalistas e informales de relaciones laborales ${ }^{6}$. Durante los años 90', la presencia de marroquíes se torna habitual, señalan los autores. Su instalación en las pedanías y en el campo anuncia el proceso de exclusión residencial, el rechazo y la explotación laboral que padecen, por lo que el lugar común de alojamiento suelen ser entre otros, naves abandonadas, que califican de infravivienda, cerca de las propiedades de aquellos agricultores que los emplean. Es en este momento cuando comienza a advertirse la llegada de ecuatorianos cuya inserción laboral y residencial ha sido más diversificada y por tanto más exitosa. Para los investigadores las tendencias que se inician en este período son la creciente diversificación de orígenes nacionales, la consecuente heterogeneidad del conjunto de la población inmigrante y la conformación de una migración familiar.

Cada uno de los grupos de inmigrantes que hasta el presente se han instalado en el área estudiada ha sufrido, en alguna medida, las prácticas de irregularidad laboral que los agricultores han ido incorporando como modelo normalizado de relación laboral. Sin embargo, para algunos de ellos ha sido más difícil experimentar una movilidad laboral ascendente, como es el caso del vecindario marroquí. Esto es conclusivo del estudio del trabajo inmigrante y su inserción laboral, como lo es, igualmente, que ha sido el colectivo ecuatoriano el que ha tenido una inserción más diversificada y una mayor movilidad. Un apartado especial se ha dedicado a la mujer trabajadora migrante cuya regularización administrativa, adquirida en ocasiones mediante los procedimientos propios de la reagrupación familiar, incide en el modo en que logra insertarse laboralmente. Asimismo el sistema de género, tanto el de origen como el de destino, tiene su reflejo en este problema siendo el servicio doméstico y la atención a familiares dependientes -cuidado de ancianos, niños, etc. - el nicho laboral en el que suelen insertarse, al lado de otros como el empaque de frutas en almacenes agrícolas y la hostelería. A estas variables se suman la del origen nacional, siendo la inserción laboral de las marroquíes diversa de aquella que experimentan las ecuatorianas. En mayor medida estas últimas realizan itinerarios en los que se observa una movilidad laboral ascendente debido, en primer lugar, a las "afinidades culturales", el conocimiento del idioma, la presunción de una mayor preparación y el tipo de proyecto migratorio que han planeado, entre otros aspectos. Sin embargo, todas ellas enfrentan un escenario donde la desregulación laboral suele ser una constante. Todo lo hasta aquí comentado revela como el proceso de estratificación étnico laboral, desarrollado en las dos últimas décadas del siglo

\footnotetext{
${ }^{6}$ Pedreño, A. (1999) "Construyendo la huerta de Europa: trabajadores sin ciudadanía y nómadas permanentes en la agricultura murciana", Migraciones, 5, 87-120. Según cita y bibliografía tomada de los autores.
} 


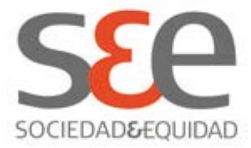

$X X$, ha consolidado un contexto de segregación que obstaculiza la sana integración de futuras generaciones.

La inserción residencial es un tema que en este trabajo se aborda con especial cuidado tratando de comprender el funcionamiento del sub-mercado de la vivienda para inmigrantes, las razones de su aparición y sus efectos en el proceso de inserción social de los extranjeros. Según los autores por régimen de tenencia de la vivienda que disfrutan o padecen los inmigrantes en los distintos municipios estudiados, se pone de relieve cómo el sesgo socio-económico como el étnico operan en contra de una integración social saludable. Son, en efecto, los estereotipos negativos y las prácticas discriminatorias los que propician la segmentación del mercado de la vivienda por la que los extranjeros se encuentran compelidos a poblar determinado tipo de morada. El paisaje que esta dinámica de exclusión lo componen tanto las chabolas, la vivienda antigua y muy degradada, las naves abandonadas, en las que el problema del hacinamiento llega a ser una variable estable. No obstante, esta situación ha ido cambiando en el tiempo y la investigación, rica en detalles, evidencia una evolución de la distribución residencial de los inmigrantes gracias a una triple dinámica, al decir de los autores, de la infravivienda al hacinamiento, del alquiler a la diversidad de situaciones, de las "afueras" a los núcleos urbanos de los municipios. El resultado de estas dinámicas sobre el proceso de inserción residencial es diverso dependiendo de los distintos colectivos inmigrantes.

A groso modo, han sido los marroquíes los que han presentado mayores dificultades para acceder a una vivienda de mayor calidad en mejores condiciones contractuales a diferencia de los latinoamericanos que gozan de una mejor vivienda, a pesar del alto grado de hacinamiento al que son sometidos.

Otros aspectos del problema, tales como la inserción escolar, el acceso a la sanidad y los servicios sociales, las relaciones de vecinos y la participación cívica constituyen, sin duda, ejes de análisis o dimensiones, al decir de los autores, igualmente relevantes para comprender la condición social y predecir tendencias futuras. Es por ellos que se han integrado en este estudio, el que ha servido como ejemplo a investigadores españoles y, de seguro, va a servir para los científicos sociales que ahora en Chile se ocupan del fenómeno migratorio. 


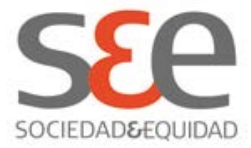

\section{Referencias Bibliográficas}

Achón, O. (2011) Inmigración, Exclusión Residencial y Segregación Espacial. Estudio sobre la vivienda inmigrante en un municipio de Lleida. Saarbrücken: Editorial Académica Española.

Martínez Veiga, U. (1999) Pobreza, segregación y exclusión espacial. La vivienda de los inmigrantes extranjeros en España, Barcelona: Icária.

Pedreño, A. (1999) "Construyendo la huerta de Europa: trabajadores sin ciudadanía y nómadas permanentes en la agricultura murciana", Migraciones, $5,87-120$.

Pedreño, A. (2005) Sociedades etnofragmentadas, en Andrés Pedreño Cánovas y Manuel Hernández Pedreño (eds.) La condición inmigrante. Exploraciones e investigaciones desde la Región de Murcia, 75-103.

Torres, F. y Gadea, E. (2010) “Inserción laboral de los inmigrantes, estructura etno-fragmentada y crisis económica. El caso del Campo de Cartagena (Murcia)" Sociología del trabaj 0, 69, 73-94.

Sayad, A. (1994) “Qu'est-ce que I'intégration », Hommes \& Migrations, 1182, 814. 